Jurnal Terapung : Ilmu - Ilmu Sosial , Vol. 2, No. 2, September 2020 ISSN: 2656-2928

\title{
METODE PEMBELAJARAN BERBASIS WEB (E-LEARNING) DALAM PROSES BELAJAR MENGAJAR SECARA VIRTUAL
}

\author{
Yanti Fauziah \\ Dosen Akademi Kebidanan Yapkesbi Banjarbaru \\ Emal: yantifauziah84@gmail.com
}

\begin{abstract}
ABSTRAK
Pembelajaran berbasis web yang populer dengan sebutan Web-Based Education (WBE) atau kadang disebut e-learning (electronic learning) dapat didefinisikan sebagai aplikasi teknologi web dalam dunia pembelajaran untuk sebuah proses pendidikan. Secara sederhana dapat dikatakan bahwa semua pembelajaran dilakukan dengan memanfaatkan teknologi internet dan selama proses belajar dirasakan terjadi oleh yang mengikutinya, maka kegiatan itu dapat disebut sebagai pembelajaran berbasis web. Saat ini paradigma pembelajaran telah berubah dari teacher-centered learning (belajar yang berpusat pada guru) ke student-centered learning (belajar yang berpusat pada pembelajar), yang ditandai dengan keaktifan pebelajar dalam proses pembelajaran, dan diasumsikan pembelajar memiliki tanggung jawab atas kegiatan belajarnya sendiri. Pembelajaran tradisional tatap muka berkaitan dengan pembelajaran di kelas yang menganggap guru sebagai ahli, penyampai pesan utama, dan satu-satunya penilaian kegiatan pembalajaran.
\end{abstract}

Kata kunci: pembelajaran berbasis web, proses belajar mengaar virtual

\begin{abstract}
Web-based learning which is popularly known as Web-Based Education (WBE) or sometimes called e-learning (electronic learning) can be defined as the application of web technology in the world of learning for an educational process. In simple terms it can be said that all learning is carried out by utilizing internet technology and as long as the learning process is felt by those who follow it, this activity can be called web-based learning. Currently the learning paradigm has changed from teacher-centered learning to studentcentered learning, which is characterized by the activeness of learners in the learning process, and it is assumed that learners have responsibility for their own learning activities. Face-toface traditional learning relates to classroom learning that considers the teacher to be the expert, the main messenger, and the only assessment of learning activities.
\end{abstract}

Keywords: web-based learning, virtual teaching learning process

\section{PENDAHULUAN}

Perkembangan teknologi yang sangat pesat sangat berpengaruh dalam dunia pendidikan. Dengan berkembangnya teknologi ini mengakibatkan berkembangnya ilmu pengetahuan yang memiliki dampak positif maupun negatif. Perkembangan teknologi ini dimulai dari negara maju, sehingga Indonesia sebagai negara berkembang perlu mensejajarkan diri dengan negara-negara yang sudah maju tersebut. 
Perkembangan ilmu pengetahuan dan teknologi semakin mendorong upaya-upaya pembaharuan dalam pemanfaatan hasil-hasil teknologi dalam proses belajar. Para guru dituntut agar mampu menggunakan alat-alat yang dapat disediakan oleh sekolah, dan tidak tertutup kemungkinan bahwa alat-alat tersebut sesuai dengan perkembangan dan tuntutan zaman. Guru sekurang-kurangnya dapat menggunakan alat yang murah dan efisien meskipun sederhana dan bersahaja tetapi merupakan keharusan dalam upaya mencapai tujuan pengajaran yang diharapkan. Disamping mampu menggunakan alat-alat yang tersedia, guru juga dituntut untuk dapat mengembangkan ketrampilan membuat media pengajaran yang akan digunakannya apabila media tersebut belum tersedia. Untuk itu guru harus memiliki pengetahuan dan pemahamaan yang cukup tentang media pengajaran.

Dari beberapa model pembelajaran, ada model pembelajaran yang menarik dan dapat memicu peningkatan penalaran siswa yaitu model pembelajaran berbasis web. Pada dasarnya, pembelajaran berbasis web adalah suatu sistem pengajaran yang cocok dengan otak yang menghasilkan makna dengan menghubungkan muatan akademik dengan konteks teknologi.

Pembelajaran berbasis web yang populer dengan sebutan Web-Based Education (WBE) atau kadang disebut e-learning (electronic learning) dapat didefinisikan sebagai aplikasi teknologi web dalam dunia pembelajaran untuk sebuah proses pendidikan. Secara sederhana dapat dikatakan bahwa semua pembelajaran dilakukan dengan memanfaatkan teknologi internet dan selama proses belajar dirasakan terjadi oleh yang mengikutinya, maka kegiatan itu dapat disebut sebagai pembelajaran berbasis web.

Kemudian yang ditawarkan oleh teknologi ini adalah kecepatan dan tidak terbatasnya tempat dan waktu untuk mengakses informasi. Kegiatan belajar dapat dengan mudah dilakukan oleh peserta didik kapan saja dan dimana saja dirasakan aman oleh peserta didik tersebut. batas ruang, jarak dan waktu tidak lagi menjadi masalah yang rumit untuk dipecahkan. Bagaimana cara belajar melalui web? Ada persyaratan utama yang pelru dipenuhi, yaitu adanya akses dengan sumber informasi melalui internet. Selanjutnya, adanya informasi tentang letak sumber informasi yang ingin kita dapatkan. Ada beberapa sumber data yang dapat diakses dengan bebas dan gratis tanpa proses administrasi pengaksesan yang rumit. Ada beberapa sumber informasi yang memang telah diberi otorosiasi pemilik sumber informasi.

Proses pembelajaran di jaman berkembangnya teknologi informasi dan komunikasi (TIK) seperti saat ini memungkinkan ketidakhadiran guru dalam kelas. Proses pembelajaran tidak lagi bergantung pada guru sebagai satu-satunya sumber belajar, dan dapat berlangsung kapan saja dan di mana saja. Proses pembelajaran tidak lagi hanya berbentuk komunikasi verbal antara guru dan siswa. Dengan pesatnya perkembangan TIK di dunia pendidikan, dengan internet sebagai bagian integral di dalamnya, banyak lembaga pendidikan yang menawarkan pembelajaran berbasis web, atau yang sering disebut dengan pembelajaran online atau e-Learning. Jenis pembelajaran seperti ini tentu saja membutuhkan pengelolaan yang baik dan maksimal, agar tujuan pembelajaran dapat tercapai. 
Dengan segala kemudahan dan kelebihan yang diberikan aplikasi pembelajaran eLearning, hal tersebut tidak diartikan dengan menghilangkan atau menggantikan peran seorang guru dalam pembelajaran. Perlu dipahami bahwa teknologi internet hanyalah berperan sebagai media yang jika dimanfaatkan dalam pembelajaran akan banyak membantu, tetapi penggunaan teknologi dalam proses pembelajaran tidak dapat mengambil alih seluruh peran seorang pengajar. Harus disadari juga bahwayang menjadi kunci utama dalam proses pembelajaran adalah tetap pendidikan itu sendiri, yang di dalamnya terkandung interaksi, baik guru dengan siswa maupun siswa dengan siswa. e-Learning juga dapat mempersingkat jadwal target waktu pembelajaran, dan tentu saja menghemat biaya yang harus dikeluarkan oleh sebuah program pendidikan. e-Learning merupakan salah satu bentuk metode pembelajaran yang dipersepsikan bersifat student centered. Pemanfaatan e-Learning diharapkan dapat memotivasi peningkatan kualitas pendidikan di Indonesia.

\section{METODE PENELITIAN}

Penelitian ini mencoba membuat gambaran secara sistematis tentang bagaimana metode pembelajaran berbasis web (e-learning) dalam proses belajar mengajar pada situasi pandemi covid-19. proses penelitian ini merupakan sesuatu yang lebih penting dibanding dengan 'hasil' yang diperoleh. Karena itu peneliti sebagai instrumen pengumpul data merupakan satu prinsip utama. Khusus dalam proses analisis dan pengambilan kesimpulan, penelitian kualitatif yang dilakukan adalah menggunakan induksi analitis (analytic induction) dan ekstrapolasi (extrpolation). Induksi analitis adalah satu pendekatan pengolahan data ke dalam konsep-konsep dan kateori-kategori (bukan frekuensi). Jadi simbol-simbol yang digunakan tidak dalam bentuk numerik, melainkan dalam bentuk deskripsi, yang ditempuh dengan cara merubah data ke formulasi. Sedangkan ekstrapolasi adalah suatu cara pengambilan kesimpulan yang dilakukan simultan pada saat proses induksi analitis dan dilakukan secara bertahap dari satu kasus ke kasus lainnya, kemudian dari proses analisis itu dirumuskan suatu pernyataan teoritis. Contohnya adalah observasi hanya mengamati masalah yang terjadi, kemudian wawancara untuk memberikan pertanyaan berkaitan dengan masalah yang akan diteliti, sehingga ditemukan hasil yang akurat berdasarkan temuan dilapangan dengan jawaban yang diperoleh.

\section{HASIL PEMBAHASAN}

\section{A. Implementasi Pembelajaran Berbasis WEB}

Model pembelajaran dirancang dengan mengintegerasikan pembelajaran berbasis web dalam progam pembelajaran konvensional tatap muka. Proses pembelajaran konvensional tatap muka dilakuakan dengan pendekatan student centered learning (SCL) melauli kerja kelompok model ini menuntut partisipasi peserta didik yang tinggi.

Untuk merancang dan mengimplementasikan pembelajaran berbasis web, langkahnya adalah sebagai berikut.

1. Sebuah progam pendidikan untuk peningkatan mutu pembelajaran di lingkungan kampus dengan berbasis web. Progam ini dialkukan idealnya selama 5-10 bulan dan 
dibagi menjadi 5 tahap. Tahap 1, 3, dan 5 dilakukan secara jarak jauh dan untuk dipilih media web sebagai alat komunikasi. Sedangakan tahap 2 dan 4 dilakukan secara konvensional dengan tatap muka.

2. Menetapkan sebuah mata kuliah pilihan di jurusan. Pembelajaran dengan tatap muka dilakukan secara rutin tiap minggu pada tujuh mingggu pertama. Setelah itu, tatap muka dilakukan setiap 2 atau 3 minggu sekali.

3. Dua progam pendidikan itu disampaikan melalui berbagai macam kegiatan belajar secara kelompok. Belajar dan mengerjakan tugas secara kolaberatif dalam kelompok sangat dominan pada kedua progamtersebut.

\section{B. Interaksi Tatap Muka dan Virtual}

Sekalipun teknologi web memungkinkan pembelajaran dilakukan virtual secara penuh, namun kesempatan itu tidak dipilih. Interaksi satu sama lain untuk dapat berkomunikasi langsung secara tatap muka masih dibutuhkan. Ada tiga alasan mengapa forum tatap muka masih dibutuhkan dalam kegiatan pembelajaran ini. Alasan tersebut adalah:

1. Perlunya forum untuk menjelaskan maksud dan mekanisme belajar yang akan dilalui bersama secara langsung dengan semua peserta didik. Keberhasilan sebuah proses pembelajaran juga ditentukan oleh pemahaman peserta didik tentang apa, mengapan dan bagaimana proses belajar dan mengerjakan tugas berlangsung. Peserta didik perlu mengetahui keluaran dan kompetensi apa yang akan didapat setelah mengikuti suatu kegiatan pembelajaran.

2. Perlunya memberikan pemahaman sekaligus pengalaman belajar dengan mengerjakan tugas secara kelompok dan kolaberatif pada setiap peserta didik. Karena model pembelajaran yang dirancang menuntut kerja kelompok, maka peserta didik perlu memiliki kompetensi dan komunikasi. Iklim partisipatoris dan aktif terlibat dalam berbagai kegiatan perlu dikenalkan sekaligus dialami oleh setiap siswa. Untuk itu, mengenal pribadi satu dengan yang lain perlu dilakukan secara langsung guna membangun suatu kelompok yang kokoh, selama kerja secara virtual.

3. Perlunya pemberian pelatihan sekupnya dalam mengggunakan komputer yang akan digunakan sebagai media komunikasi berbasis web kepada setiap peserta didik. Dengan menyertakan berbagai kegiatan menggunakan komputer beserta fasilitas sistem komunikasi pendukungnya, maka setiap pesrta didik harus mempunyai ketrampilan mengoperasikanya.

Di negara-negara maju seperti Amerika seriakat, teknologi informasi sudah betulbetul merasuk ke dalam kehidupan sehari-hari. Dalam berbagai hal dapat kita lihat implikasinya.

Sejarah teknologi informasi tidak dapat dilepaskan dari bidang pendidikan. Di Amerika TI mulai tumbuh dari lingkungan akademis (NSFNET). Demikian di Indonesia, TI mulai tumbuh di lingkungan akademis seperti di ITB, UPI, dan UI. Adanya TI atau 
internet membuka sumber informasi yang tadinya susah di akses . Akses terhadap sumber informasi bukan menjadi masalah lagi. Perpustakaan merupakn salah satu sumber informasi yang mahal harganya. Adanya jaringan TI atau internet memungkinkan seseorang di indonesia untuk mengakses perpustakaan di Amerika Serikat. Tanpa adanya internet banyak tugas akhir, tesis dan disertasi yang mungkin membutuhkan waktu yang lebih banyak untuk diselesaikan.

Kerja sama antarahli dan juga dengan mahasiswa yang letaknya berjauhan secara fisik dapat dilakukan dengan lebih mudah. Dahulu seseorang harus berkelana atau berjalan jauh untuk menemui seseorang pakar untuk mendiskusiakn sebuah masalah. Saat ini hal ini dapat dilakukan dari rumah dengan mengirimkan e-mail. Makalah dan penelitian dapat dilakukan dengan silang tukar menukar data melalui internet, via email, ataupun dengan mengggunakan mekanisme file sharing, jadi disini batasan geografis bukan menjadi masalah lagi.

Bagi Indonesia, manfaat-manfaat yang disebutkan di atas sudah dapat menjadi alasan yang kuat untuk menjadikan internet sebagai infrastruktur bidang pendidikan. Dalam kegiatan pembelajaran dengan munculnya berbagai software yang dapat digunakan untuk kepentingan pembelajaran, sekarang ini para guru dapat merancang pembelajaran berbasis komputer, dengan menggunakan salah satu bahasa pemograman seperti delphi, pascal, makromedia flash, swiss MX dan lainya. Hal ini dapat memberikan variasi dalam mengajar. Seorang guru tidak harus menjejali siswa dengan informasi yang membosankan. Dengan menggunakan teknologi informasi seorang guru dapat memanfaatkan komputer sebagai total teaching, dimana guru hanya sebagai fasilitator dan sisiwa dapat belajar dengan berbasis komputer baik dengan menggunakan model pembelajaran driils, tutorial, simulasi ataupun, instrucsioanl games

\section{Pemanfaatan Internet Sebagai Media Pembelajaran}

Internet, sigkatan dari interconnectian and networking, adlah jaringan informsi global, yaitu "The largest global network of computers, that enables people troughout the world to connnect with each other". Internet diluncurkan pertama kali oleh J.C.R Licklider dari MIT (massachusetts institute technologi) pada agustus 1962. Untuk dapat mengggunakan internet diperlukan sebuah komputer yang memadai, harddisk yang cukup, modem, sambungan telepon, aada progam windows, dan sedikit tahu cara mengoperasikanya.

Selanjutnya hubungi provider terdekat jika, andaikan semua prasarat tadi tidak dimiliki, cukup mendatangi warnet terdekat yang banyak terdapat di kota-kota besar, bahkan sampai ke desa-desa, kita dapat mengakses situs-situs apa saja sesuai dengan kebutuhan kita. Bahkan Rusman menyebutkan bahwa internet merupakan perpustakaan raksasa dunia, karena di dalam internet terdapat miliaran sumber informasi, sehingga kita dapat menggunakan informasi tersebut sesuai dengan kebutuhan.

Pemanfaatan internet sebagai media pembelajaran mengkondisikan siswa untuk belajar secara mandiri. "Through independent study, students become doars, as well as 
thinkers" (cobine, 1997). Para siswa dapat mengakses secara online dari berbagai pustakawan, museum, database, dan mendapatkan sumber primer tentang berbagai peristiwa sejarah, biografi, rekaman, laporan, dat statistik, (Gordin et. Al., 1995).

Siswa dapat berperan sebagai seorang peneliti, menjadi seorang analisis, tidak hanya konsumen informasi saja. Mereka menganilisis informasi yang relavan dengan pembelajaran IPS dan melakukan pencarian yang sesuai dengan kehiduapan nyatanya (real life). Siswa dan guru tidak perlu hadir secar fisik di kelas (classroom meeting), karena siswa dapat mempelajari bahan ajar dan mengajarkan tugas-tugas pembelajaran serta ujian dengan cara mengakses jaringan komputer yang telah ditetapkan secara online. Siswa juga dapat bekerja sama satu sama lain. Mereka dapat saling berkirim e-mail untuk mendiskusikan bahan ajar. Kemudian, selain mengerjakan tugastugas pembelajaran dan menjawab pertanyaan-pertanyaan yang diberikan guru siswa dapat berkomunikasi dengan teman sekelasnya.

Pemanfaatan internet sebagai media pembelajaran memiliki beberapa kelebihan sebagai berikut.

1. Dimungkinkan terjadinya distribusii pendidikan ke semua penjuru tanah air dan kapasitas daya tampung yang tidak terbatas karena tidak memerlukan ruang kelas.

2. Proses pembelajaran tidak terbatas oleh waktu seperti halnya tatap muka biasa.

3. Pembelajaran dapat memilh topik atau bahan ajar yang sesuai dengan keinginan dan kebutuhan masing-masing.

4. Lama waktu belajar juga tergantung pada kemampuan masing-masing siswa.

5. Adanya keakuratan dan kekinian materi pembelajaran.

6. 6.Pembelajran dapat dilakukan secara interaktif, sehingga menarik siswa; dan memungkinkan pihak berkepentingan (orang tua siswa maupun guru) dapat turut serta menyukseskan proses pembelajaran, dengan cara mengecek tugas-tugas yang dikerjakan siswa secara online

Perkembangan/kemajuan teknologi internet yang sangat pesat dan merambah keseluruh penjuru dunia telah dimanfaatkan oleh berbagai negara, institusi d.an ahli untuk berbagai kepentingan termasuk di dalamnya untuk pendidikan/pembelajaran. Berbagai percobaan untuk mengembangkan perangkat lunak (progam aplikasi) yang dapat menunjang upaya peningkatan mutu pendidikan/pembelajaran terus dilakukan.

\section{Penggunaan dan peran Internet dalam Pembelajaran}

Internet merupakan sebuah jaringan global yang merupakan kumpulan dari jaringan-jaringan komputer di seluruh dunia. Internet mempermudah para pemakainya untuk mendaptkan informasi-informasi di dunia cyber, lembaga-lembaga milik pemerintah, dan institusi pendidikan dengan menggunakan kumunikasi protokol yang terdapat pada komputer, seperti transmisssion Control protocol (TCP), TCP merupkan suatu protokol yang sanggup memungkinkan sistem apapun sehingga antar sisitem jaringan komputer dapat berkomunikasi baik secara lokal maupun internasional dengan modus koneksi serial line internet protocol (SLIP) point to point protocol (PPP).Tahun 
1983 merupakan tahun kelahiran internet yang ditandai dengan diadopsinya transmission control (TCP) sebagai standar bagi aparnet. Protokol yang lainya adalah IP (Internet protocol).

Berikut ini hal-hal yang dapat difasilitasi oleh adanya internet, yaitu:

1. Discovery (penemuan), ini meloputi browsing dan pencarian nformasi-informasi tertentu

2. Communication (komunikasi), internet menyediakan jaringan komunikasi yang cepat dan murah mulai dari pesan-pesan yang berupa buletin sampai dengan pertukaran komunikasi yang bersifat kompleks antar atau inter organisasi. Juga termasuk diantaranya transfer informasi (antarkomputer) dan proses informasi. Adapun contoh-contoh media komunikasi yang utama seperti e-mail, chat group (percakapan secar berkelompok), dan news group (gabiungan kelompok yang bertukar berita).

3. Collaboration (kolaborasi), seiring dengan semakin meningkatnya komunikasi dan kolaborasi antar media elektronik, baik itu antar individu maupun antarkelompok, maka beberapa fasilitas canggih dan modern pun digunakan mulai dari screen sharing (pertukaran sumber-sumber informasi), yang menyediakan akses pada server-server yang sesuai dengs bidangnya masing-masing.

Peranan internet dalam pendidian sangat menguntungkan karena kemampuanya dalam mengelola data dengan jumlah yang sangat besar. Teknologi sudah menjadi jaringan komputer terbesar di dunia, yang dapat berfungsi dengan baik jika didukung oleh perangkat komputer dengan perangkat lunak yang baik dan dengan guru yang terlatih baik. Mengguakan internet dengan segala fasilitasnya akan memberikan kemudahan untuk mengakses berbagai informasi untuk pendidikan yang secar langsung dapat meningkatkan pengetahuan siswa bagi keberhasilanya dalam belajar. Karena internet merupakan sumber informasi utama dan pengetahuan, melalui teknologi ini kita dapat melakukan beberapa hal, diantaranya untuk:

1. Penulusuran dan pencarian bahan pustaka

2. Memberi kemudahan untuk mengakses apa yng disebut dengan virtual classroom atau virtual university

3. Pemasaran dan promosi hasil karya penelitian.

Kegunaaan-kegunaan seperti diatas itu dapat diperluas bergantung pada peralatan komputer yang dimiliki, jaringan dan fasilitas telepon yang tersedia, serta provider yang bertanggung jawab agar penggunaan jaringan komunikasi dan informasi tersebut tetap terpelihara. Dari waktu ke waktu, jika dilihat dari jumlah pemakaian yang makin meningkat secar eksponensial, setiap tahunya memungkinkan fasilitas yang pada mulanya hanya dinikmati segelintir orang, dan sekelompok kecil sekolah terkemuka dengan biaya operasional yang tinggi, ke depan besar kemungkinan biaya yang besar itu akan dapt ditekan, sehingga pemanfaatanya benar-benar dapt menjadi penunjang utama bagi pengelola pendidikan khususnya bagi pusat sumber belajar bagi kegiatan pendidikan di daerah. 


\section{E. PemanfaatanE-Leaning untuk Pembelajaran}

Menurut Jaya Kumar C. Koran (2002), e-learning adalah pembelajaran yang menggunakan rangkaian elektronik (LAN, WAN, atau internet) untuk menyampaikan isi pembelajaran, interaksi atau bimbingan. Ada pula yang menafsirkan e-learning sebagi bentuk pendidikan jarak jauh yang dilakukan melalui media internet, sedangkan Dong mendefinisikan e-learning sebagai kegioatan belajar asynchronous melalui perangkat elektronik komputer yang memperoleh bahan belajar yang sesuai dengan kebutuhanya.

Rosenberg (2001) menekankan bahwa e-learning merujuk pada penggunaan teknologi internet untuk mengirimkan seraingkain solusi yang dapat meningkatkan pengetahuan dan ketrampilan. Hal ini senada dengan Campbell (2002), Kamarga (2002) yang intinya menekankan penggunaan internet dalam pendidikan sebagai hakikat elearning

Perbedaan pembelajaran tradisional dengan e-learning, yaitu kelas tradisional. Guru dianggap sebagai orang yang serba tahu dan ditugaskan untuk menyalurkan ilmu pengetahuan kepada pelajarnya. Sedangkan di dalam pembelajaran e-learning fokus utamanya adalah pelajar. Pelajar mandri pada waktu tertentu dan bertanggung jawab untuk pembelajaranya. Suasana pembelajaran e-learning akan memaksa pelajar memainkan peranan yang lebih aktif dalam pembelajaranya. Pelajar membuat perancangan dan mencari materi dengan usaha dan inisiatif sendiri.

Sedangkan karakteristik e-learning, antara lain; pertama, memanfaatkan jasa teknologi elektronik; di mana guru dan siswa, siswa dan sesama siswa atau guru dan sesama guru dapat berkomunikasi dengan relatif mudah dengan tanpa dibatasi oleh halhal yang protokol. Kedua, memanfaatkan keunggulan komputer. ketiga, menggunakan bahan ajar bersifat mandiri disimpan dikomputer sehingga dapat di akses oleh guru dan siswa kapan saja dan dimana saja bila yang bersangkutan memerlukanya. Keempat, memanfaatkan jadwal pembelajaran, kurikulum, hasil kemajuan belajar, dal hal-hal yang berkaitan dengan administrasi pendidikan dapat dilihat setiap saat di komputer.

1. Pengembangan Model E-Leraning

Pendapat haughey (Rusman, 2007) tentang pengembangan e-learning adalah ada tiga kemungkinan dalam pengembangan sistem pembelajaran berbasis internet, yaitu web course, web centric course, dan web enhanced course.

Web course adalah penggunaan untuk keperluan pendidikan, yang mana mahasiswa dan dosen sepenuhnya terpisah dan tidak diperlukan adanya tatap muka. Seluruh bahan ajar, diskusi, konsultasi, penugasan, latihan, ujian, dan kegiatan pembelajaran lainya sepenuhnya disampaikan melalui internet.

Web centric course adalah penggunaan internet yang memadukan antara belajar jarak jauh dan tatap muka. Sebagaian materi disampaikan melalui internet, dan sebagaian lagi melalui tatap muka, fungsinya saling melengkapi. 
Web enhanced course adalah pemanfaatan internet untuk menunjang peningkatan kualitas pembelajaran yang dilakukan di kelas. Fungsi internet adalah untuk memberikan pengayaan dan komunikasi antara mahasiswa dengan dosen, sesama mahasiswa, anggota kelompok, atau mahasiswa dengan narasumber lain.

2. KelebihandanKekurangan E-Learning

Petunjuk tentang manfaat penggunaan internet, khususnya dalam pendidikan terbuka dan jarak jauh, antara lain:

a. Tersedianya fasilitas e-moderating di mana pendidikan dan peserta didik dapat berkomunikasi secara mudah melalui fasilitas internet secara reguler atau kapan saja kegiatan berkomunikasi itu dilakukan dengan tanpa dibitasi oleh jarak, tempat, dan waktu.

b. Pendidikan dan peserta didik dapat menggunakan bahan ajar atau petunjuk belajar yang terstruktur dan terjadwal melalui internet, sehingga keduanya bisa saling menilai sampai berapa jauh bahan ajar dipelajari.

c. Peserta didik dapat belajar atau me-review bahan pelajaran setiap saat dan dimana saja kalau diperlukan, mengingat bahan ajar tersimpan di komputer

d. Bila peserta didik memerlukan tambahan informasi yang berkaitan dengan bahan yang dipelajarinya, ia dapat melakukan akses di internet secara lebih mudah.

e. Baik pendidik maupun peserta didik dapat melakukan diskusi melalui internet yang dapat diikuti dengan jumlah peserta yang banyak, sehingga menambah ilmu pengetahuan dan wawasan yang lebih luas.

\section{KESIMPULAN}

Pembelajaran berbasis web (e-Learning) didefinisikan sebagai aplikasi teknologi web dalam dunia pembelajaran untuk sebuah proses pendidikan.

Pemanfaatan internet sebagai media pembelajaran mengkondisikan siswa untuk belajar secara mandiri. Para siswa dapat mengakses secara online dari berbagai pustakawan, museum, database, dan mendapatkan sumber primer tentang berbagai peristiwa sejarah, biografi, rekaman, laporan, dat statistic. Siswa dapat berperan sebagai seorang peneliti, menjadi seorang analisis, tidak hanya konsumen informasi saja.

Peranan internet dalam pendidian sangat menguntungkan karena kemampuanya dalam mengelola data dengan jumlah yang sangat besar. Teknologi sudah menjadi jaringan komputer terbesar di dunia, yang dapat berfungsi dengan baik jika didukung oleh perangkat komputer dengan perangkat lunak yang baik dan dengan guru yang terlatih baik.

Perbedaan pembelajaran tradisional dengan e-learning, yaitu kelas tradisional. Guru dianggap sebagai orang yang serba tahu dan ditugaskan untuk menyalurkan ilmu pengetahuan kepada pelajarnya. Sedangkan di dalam pembelajaran e-learning fokus utamanya adalah pelajar

\section{DAFTAR PUSTAKA}


Alamaki, A. 1999. Current Trends in Technology Education in Finland. The Journal of Technology Studies. Available on: Digital Library and Archives.

Barron, B.J., Schwartz, D.L., Vey, N.J., Moore, A., Petrosino, A., Zech, L., Bransford, J. D., \& The Cognition and Technology Group at Vanderbilt. 1998. Doing with Understnading: Lessons from Research on Problem- and Project-Based Learning. The Journal of the Learning Science, 7, 271-311.

Buck Institutute for Education. 1999. Project-Based Learning. http://www.bgsu.edu/organizations/etl/proj.html.

Budiasih, E., Widarti, H.R. 2004. Penerapan Pendekatan Daur Belajar (Learning Cycle) dalam Pembelajaran Matakuliah Praktikum Kimia Analisis Instrumen. Jurnal Pendidikan dan pembelajaran Vol 10 (1), hal 70-78.

Dryden, Gordon dan Jeanette Vos. 1999. The Learning Revolution: To Change the Way the World Learns. Selandia Baru: The Learning Web.

Herschbach, D.R.1999. Looking Past 2000. Dalam Technology Education in Prospect: Perceptions, Change, and the Survival of the Profession. The Journal of Technology Studies. Digital Library and Archives.

Householder, D.L. 1999. View in Technology Education in Prospect: Perceptions, Change, and the Survival of the Profession. The Journal of Technology Studies. Digital Library and Archives.

Hung, D.W., \& Wong, A.F.L. 2000. Activity Theory as a Framework fo Project Work in Learning Environments. Educational Technology, 40(2), 33-37.

Johnson, D.W., \& Johnson, R.T. 1989. Social Skills for Successful Gorup Work. Educational Leadership, 47(4), 29-33.

Ngalimun. 2014. Strategi dan Model Pembelajaran. Yogyakarta: Aswaja Pressindo

Ngalimun, Nur Fuadi Rahman, Latifah. 2020. Dakwah KH. Zainuri HB dan Peran Kepemimpinannya di Pesantren. Sahafa Journal of Islamic Communication (SJIC) ISSN: 2622-4313Vol. 3 No. 1. DOI: http://dx.doi.org/10.21111/sjic.v3i1.4602

Oakey, J. 1998. Project-Based and Problem-Based: The Same or Different? http://pblmm.k12.us/PBLGuide/PBL\&PBL.html

Richmond, G., \& Striley, J. 1996. Making Meaning in Classrooms: Social Processes in

Sofyan Amri dan Iif Khoiru Ahmadi. 2010. Kontruksi Pengembangan Pembelajaran. Jakarta: Prestasi Pustaka.

Skeel, D.J. 1995. Elementary Social Studies: Challenge for Tomarrow”s World. New York: Harcourt Brace College Publishers.

Sumarjo, H. 2003. Menyongsong UU Sisdiknas yang Baru. Kompas. 13 Maret 2003. Hlm.6.

Shia, R.M., Howard, B.C., \& McGee, S. 1998. Metacognition, Multiple Intelligence and Cooperative Learning. http://www.cet.edu/research/student.html.

Trilling, B., \& Hood, P. 1999. Learning, Technology, and Education Reform in the Knowledge Age, or “We're Wired, Webbed, and Windowed, Now What?”. Educational Technology, Mey-Juni, 5-18.

Wena, M. 2009. Strategi Pembelajaran Inovatif Kontemporer. Jakarta: Prestasi Pustaka 